\title{
ANTROPOLOGIA DA DÁDIVA EM GRANDE SERTÃO: VEREDAS
}

\author{
Anthropology of the gift in Grande sertão: veredas
}

Claudio Santana Pimentel ${ }^{1}$

\begin{abstract}
RESUMO: Este artigo propõe, a partir de um diálogo entre ciência da religião e literatura, oferecer subsídios para o estudo das relações entre a literatura brasileira e a religião. Para isso, parte de uma definição aberta e funcional de religião, e considera que a seu modo religião e literatura são expressões simbólicas da experiência humana em sua compreensão de mundo. A título de exemplo, examina a relação entre religião e literatura no romance Grande Sertão: veredas, de Guimarães Rosa, tendo como referência o trabalho da pesquisadora Ursulina Santana, que permite compreender a presença, no romance, de uma antropologia da dádiva, a partir da análise da sacralização do alimento, percebido como dádiva divina, estabelecendo entre as pessoas vínculos de solidariedade, hospitalidade e comensalidade.
\end{abstract}

PALAVRAS-CHAVE: Alimento; Dádiva; Literatura; Religião; Expressões Simbólicas.

ABSTRACT: This article proposes, from a dialogue between the science of religion and literature, to offer subsidies for the study of the relationship between Brazilian literature and religion. For this, it starts from an open and functional definition of religion, and considers that, in their own way, religion and literature are symbolic expressions of human experience in its understanding of the world. As an example, it examines the relationship between religion and literature in the novel Grande Sertão: veredas, by Guimarães Rosa, having as reference the work of researcher Ursulina Santana, which allows us to understand the presence, in the novel, of an anthropology of the gift, based on from the analysis of the sacralization of food, perceived as a divine gift, establishing bonds of solidarity, hospitality and commensality between people.

KEYWORDS: Food; Gift; Literature; Religion; Symbolic Expressions.

"Quem sabe direito o que uma pessoa é? Antes sendo: julgamento é sempre defeituoso, porque a gente julga é o passado. Eh, bê. Mas, para o escriturado da vida, o julgar não se dispensa; carece? Só que uns peixes tem, que nadam rio-arriba, da barra às cabeceiras. Lei é lei? Lôas! Quem julga já morreu. Viver é muito perigoso mesmo.”2

\footnotetext{
${ }^{1}$ Doutor em Ciências da Religião pela Pontifícia Universidade Católica de São Paulo (PUC-SP) e professor no Instituto São Paulo de Estudos Superiores (ITESP) e na Secretaria da Educação do Estado de São Paulo. E-mail: pimentelclaudio@live.com

${ }^{2}$ ROSA, João Guimarães. Grande sertão: veredas. 19. ed. Rio de Janeiro: Nova Fronteira, 2001.
} 
"O compartilhar o alimento, a refeição, permite que seja expressa a mística sertaneja, quando ao dividir a comida entre os pares e por todos que habitam o espaço sertanejo laços de convivialidade, alteridade, solidariedade, gratuidade, generosidade sejam percebidos na circularidade da dádiva. A comida deixa de ter apenas o valor nutricional passando a esfera do sagrado, em sua dimensão objetiva."3

O presente artigo, ${ }^{4}$ divido em três partes, tece considerações sobre a relação entre religião e literatura, com especial olhar para o contexto brasileiro. Diante disto, considero como ponto de partida que, cada uma a seu modo, religião e literatura são meios pelos quais o ser humano procura expressar simbolicamente sua compreensão de si e do mundo.

$\mathrm{Na}$ primeira parte do artigo, desenvolvo essa ideia a partir de duas maneiras de compreender a literatura que permitem aproximá-la da religião, considerando a literatura como capacidade de ficcionar e como expressão de uma experiência espiritual.

Por outro lado, trabalho com uma definição funcional de religião, considerando este conceito como capaz de descrever fenômenos presentes nas diversas culturas humanas.

O que chamamos de "religião" tem-se manifestado, no decorrer da história e em todas as partes do mundo, em diversificações e diferenças múltiplas. De acordo com essa complexidade, não é possível pensar em uma definição fechada de religião, mas optar por certo conceito aberto capaz de superar um entendimento pré-teórico que generaliza fenômenos religiosos, sobretudo de origem cristã, com os quais estamos culturalmente acostumados. ${ }^{5}$

Empregando uma definição aberta e funcional de religião, Frank Usarski convida a pensar as tradições religiosas para além da lógica das religiões cristãs, assumindo-a como paradigma para a interpretação de outras tradições. De outro modo, elenca algumas características que se encontram presentes no que se designa como religião: são sistemas simbólicos de compreensão/interpretação da realidade; se constituem a partir de referências a realidades transcendentais, que se encontram além da experiência imediatamente dada; se articulam em múltiplas dimensões, ou seja, englobam vários aspectos da vida humana; cumprem funções individuais e sociais.

\footnotetext{
${ }^{3}$ SANTANA, Ursulina Maria Silva. Ôôôô de Casa... Ôôôo de Fora... As cozinhas em Grande Sertão: veredas e a partilha do alimento como hierofania nos gestos sertanejos. Tese. Doutorado em Ciência da Religião. Pontifícia Universidade Católica de São Paulo, São Paulo. 2014, p. 105.

${ }^{4}$ Este texto é uma versão revista e ampliada da conferência intitulada "A religião na literatura brasileira", proferida virtualmente na abertura da V Semana Cultural: Literatura brasileira, religião e cultura, promovida pela Faculdade São Basílio Magno, Fasbam, em 04 de outubro de 2021.

5 USARSKI, Frank. Constituintes da ciência da religião: cinco ensaios em prol de uma disciplina acadêmica. São Paulo: Paulinas, 2006, p. 125.
} 
Por sua dimensão simbólica, religião e literatura encontram-se na abertura para a utopia, compreendida não como a busca do irrealizável, mas enquanto a capacidade humana de referir-se ao que está além da realidade empírica imediatamente dada, e, a partir daquilo que o transcende encontrar referenciais para a compreensão e a transformação do mundo vivido.

$\mathrm{Na}$ segunda parte do artigo, exemplifico as possibilidades de aproximação entre religião e literatura no contexto da literatura brasileira. Daí decorre a análise que se realiza na terceira parte, a partir do romance Grande sertão: veredas, de João Guimarães Rosa. Das metáforas presentes na escritura roseana, seleciono as metáforas de comunhão e de dádiva, reveladoras de uma antropologia da dádiva. Nesta segunda parte, aspectos da definição de religião mencionada acima serão retomados e exemplificados, contextualizados a partir das dinâmicas do alimento e da comensalidade e hospitalidade.

\section{Literatura e religião como expressões do humano}

Em seu conhecido ensaio sobre o direito à literatura, Antônio Candido apresenta uma definição de literatura que compreendo como a afirmação da capacidade humana de ficcionar, de elaborar narrativas simbólicas:

Chamarei de literatura, da maneira mais ampla possível, todas as criações de toque poético, ficcional ou dramático em todos os níveis de uma sociedade, em todos os tipos de cultura, desde o que chamamos folclore, lenda, chiste, até as formas mais complexas e difíceis da produção escrita das grandes civilizações.

Vista deste modo a literatura aparece claramente como manifestação universal de todos os homens em todos os tempos. Não há povo e não há homem que possa viver sem ela, isto é, sem a possibilidade de entrar em contato com alguma espécie de fabulação. ${ }^{6}$

Nessa definição, ainda que de maneira implícita, se apresenta a potencialidade da literatura de expressar a experiência espiritual. Ao discutirem, de maneira mais ampla, a capacidade da arte em geral de expressar essa experiência, Ceci Mariani e Heinrich Alexander Otten, em leitura de obras do artista plástica Wassily Kandinsky e da escritora Clarice Lispector, definem a experiência espiritual como abertura para o transcendente e como revelação.

\footnotetext{
${ }^{6}$ CÂNDIDO, Antonio. O direito à literatura. In: Vários escritos. 5. ed. Rio de Janeiro: Ouro sobre azul, 2011, p. 176.
} 
Acompanhando os autores, se pode perceber que esta é uma abertura transformadora da relação de cada pessoa com o mundo vivido e consigo mesma. A arte é, segundo Mariani e Otten, em diálogo com Alfredo Bosi, por um lado, criação, gestação de algo novo, e por outro, conhecimento, uma maneira de (re)interpretar a realidade. É ainda expressão pessoal, emergência da subjetividade. O que os permite concluir que a arte "é linguagem chamada e capacitada para a expressão da experiência espiritual, que é revelação do sentido profundo e eterno da realidade." 7

\section{Literatura brasileira e religião}

$\mathrm{Na}$ literatura brasileira, a dimensão religiosa foi abordada sob as mais diferentes perspectivas, por exemplo, em posicionamentos que criticam a realidade social assumindo a religiosidade como denúncia das injustiças, como no teatro de Ariano Suassuna,${ }^{8}$ até perspectivas que veem a religião desde um ponto de vista crítico, como em O pagador de promessas, ${ }^{9}$ de Dias Gomes.

Pode-se dizer que a literatura brasileira tem tematizado a religião, por vezes assumindo-a, ou ainda criticando-a, por encontrar na dimensão religiosa subsídios que lhe permitiram uma imersão na "alma" brasileira, uma aproximação com a cultura popular, fortemente marcada pela experiência religiosa. Por vezes encontrando nessa experiência religiosa popular uma perspectiva de resistência, frente a uma sociedade constituída de maneira violenta, assimétrica e profundamente injusta, ocasionalmente criticando essa cosmo-percepção dos simples por compreendê-la como alienante.

Em leituras de João Cabral de Mello Neto, Waldecy Tenório, assumindo a seu modo a tese feuerbachiana da religião como projeção humana, ${ }^{10}$ adverte: "Uma afirmação é

\footnotetext{
${ }^{7}$ MARIANI, Ceci Baptista e OTTEN, Heinrich Alexander. A arte como expressão da experiência espiritual: experiência de revelação e caminho de transformação. In: MARIANI, Ceci Baptista e VILHENA, Maria Angela. (Orgs.). Teologia e arte: expressões de transcendência, caminhos de renovação. São Paulo: Paulinas, 2011, p. 38.

${ }^{8}$ Cf. PIMENTEL, Claudio Santana. Humanização do divino, divinização do humano: representações do imaginário religioso no teatro de Ariano Suassuna. Dissertação. Mestrado em Ciências da Religião. Pontifícia Universidade Católica de São Paulo. São Paulo, 2010.

${ }^{9}$ Cf. SILVA, Antonio Ozaí da. Preconceito e intolerância religiosa em "O pagador de promessas". Revista Espaço Acadêmico, v. 7, n. 73, 2007.

${ }^{10}$ Cf. FEUERBACH, Ludwig. A essência do cristianismo. 5. ed. Lisboa: Fundação Calouste Gulbenkian, 2018.
} 
teológica não por se referir a um ser particular a quem chamamos Deus, mas por exprimir o sentido último de nossa existência pessoal."11

Guimarães Rosa se aproximou do modo de vida das pessoas simples e da religiosidade popular em andanças pelo sertão e no convívio com sua gente. Talvez Rosa tenha se projetado no "doutor da cidade", o interlocutor silencioso e atento, que a tudo anota, a quem Riobaldo se dirige em Grande sertão: veredas. ${ }^{12}$ É desse sertão vivido que nasce sua escritura:

Conhecedor do sertão mineiro, Guimarães descreve a vida das pessoas que ocupam um espaço que geograficamente é considerado inóspito, sujeito ao desígnio da Natureza, que para quem vive no sertão está a mercê de Deus. A lida diária com o inesperado vai criar entre essas pessoas laços de fraternidade para que possam sobreviver como grupo. Um espaço permeado pelo sagrado, manifesto nos gestos e atitudes humanas vai criar condições para produzir uma mística, onde a solidariedade, a partilha, a confraternização sejam os elos mais profundos entre os indivíduos. Sendo assim pode-se dizer que há uma mística sertaneja, visualizada por Guimarães Rosa em suas andanças no sertão. ${ }^{13}$

O romance se estrutura a partir de duas metáforas principais, o sertão e o rio, que estão sintetizadas no título Grande sertão: veredas. Adélia Bezerra de Meneses assume a premissa de Giambatista Vico, filósofo para quem a linguagem poética, metafórica, precede a linguagem pretensamente "objetiva" da prosa:

O filósofo Giambatista Vico, para quem a metáfora é um pequeno mito, no seu extraordinário Scienza Nuova, em pleno século XVII, defende a ideia de que a poesia procede a prosa, de que os homens primitivos falavam por poesia, e só posteriormente

\footnotetext{
11 TENÓRIO, Waldecy. A bailadora andaluza: a explosão do sagrado na poesia de João Cabral. Cotia: Ateliê Editorial, 1996, p. 48. Não abordarei neste artigo a relação entre teologia e literatura. Para uma síntese crítica das abordagens teológicas da obra literária no contexto brasileiro, cf. MANZATTO, Antonio. Pequeno panorama de teologia e literatura. In: MARIANI, Ceci Baptista e VILHENA, Maria Angela. (Orgs.). Teologia e arte: expressões de transcendência, caminhos de renovação. São Paulo: Paulinas, 2011, p. 38, p. 87-98.

12 “A segunda pista, já sabemos, é a seguinte: o destinatário enigmático é Deus. Mas como justificar essa hipótese? Bem, ele também é um mestre do disfarce, aparece e desaparece, Deus absconditus, age como o esgrimista de Kierkegaard: o adversário sente o golpe, é tocado, mas sempre num lugar muito diferente do que esperava. E, além disso, ele é sutil, a ponto de um teólogo como Karl Rahner ter podido defender a ideia de que o cristianismo é uma forma radical de agnosticismo. E de um Jack Milles ter dito que, de Deus, não se pode escrever uma biografia, mas uma teografia, que ele mesmo define como o movimento do discurso em direção ao silêncio. Desse modo, se o interlocutor de Riobaldo se disfarça, se esconde, silencia - e ri -, pode ser um disfarce de Deus, por que não?”. TENÓRIO, Waldecy. Outras verdades, muito extraordinárias. Estudos avançados, v. 20, 89-96 [93], 2006. A primeira pista, que o crítico termina por descartar, é a de que o interlocutor de Riobaldo seja enfim o Diabo (cf. p. 90-91).

${ }^{13}$ SANTANA, Ursulina Maria Silva. Ôôôô de Casa... Ôôôô de Fora... As cozinhas em Grande Sertão: veredas e a partilha do alimento como hierofania nos gestos sertanejos. Tese. Doutorado em Ciências da Religião. Pontifícia Universidade Católica de São Paulo, São Paulo. 2014, p. 16.
} 
a linguagem racional da prosa se instaura. Os homens, por necessidade de expressão, falariam por imagens. Disso já se infere que a fala poética não é enfeite, adorno, um refinamento tardio, mas algo de essencial, de vitalmente necessário. ${ }^{14}$

Tecendo relações entre religião e literatura, entre a linguagem religiosa e a linguagem poética, me coloco ao encalço de outras metáforas também presentes em Grande sertão: veredas; são estas as metáforas da comunhão e da dádiva.

\section{Uma antropologia da dádiva}

Em pesquisa sobre as cozinhas no Grande sertão: veredas, Ursulina Santana ${ }^{15}$ procurou compreender como as formas de sociabilidade desenvolvidas a partir da obtenção, do preparo e da partilha do alimento, as práticas de sociabilidade e comensalidade associadas à alimentação, revestem-se de caráter religioso.

A partilha do alimento coloca as pessoas em contato umas com as outras, mas também em contato com o transcendente, o que atribui significado à experiência alimentar, para além da necessidade biológica do sustento do corpo. $\mathrm{O}$ alimento e as práticas associadas a ele são constituintes das relações humanas, ressignificadas em referência ao que se encontra além da sua simples materialidade.

Leonardo Boff, ao explicar a sacralidade que conferimos às coisas, ajuda a compreender a transformação por que passa o alimento:

O pão lembra algo que não é pão. Algo que trans-cende o pão. O pão por sua vez é algo in-manente. Permanece aí. Tem seu peso. Sua composição de elementos empregados: farinha, ovos, água, sal e levedo. Sua opacidade. Esse pão (realidade inmanente) torna presente algo que não é o pão (realidade trans-cendente). Como o faz? Pelo pão e através do pão. O pão se torna então trans-parente para a realidade transcendente. Ele deixa de ser puramente in-manente. Não é mais como os demais pães. É diferente. É diferente porque recorda e traz presente por si mesmo (in-manência) e através de si mesmo (trans-parência) algo que vai além dele mesmo (transcendência). ${ }^{16}$

\footnotetext{
${ }^{14}$ MENESES, Adélia Bezerra de. O ‘Quem’ dos lugares. A passionalização da natureza em Grande sertão: veredas. Scripta, v. 9, n. 17, p. 29-39, 2005.

${ }^{15}$ Ursulina Maria Silva Santana, Sula, Doutora em Ciência da Religião, foi professora de cozinha brasileira, história e sociologia da alimentação em diversas instituições de ensino. "Encantou-se", permitindo-me empregar uma expressão roseana, em abril de 2021. Este texto é, também, homenagem e agradecimento por anos de amizade e colaboração.

${ }^{16}$ BOFF, Leonardo. Os sacramentos da vida e a vida dos sacramentos: minima sacramentalia. 26. ed. Petrópolis: Vozes, 2004, p. 28-29.
} 
Essas práticas e formas de sociabilidade em torno da alimentação se organizam em dois modos de cozinhar, que Ursulina Santana nomeia como cozinha de fora e cozinha de dentro. Uma cozinha de fora nômade, itinerante, que se apresenta na jagunçagem ${ }^{17}$ característica dos grupos paramilitares que circulavam pelo interior do Brasil entre o século XIX e a primeira metade do XX, e que se encontrava também presente na economia do gado, movimentada por tropeiros e vaqueiros; economia, como ressalta a autora, fundamental para a interiorização da população brasileira, criando as condições para que esta, afastada do litoral e de suas facilidades, se tornasse sedentária. A interiorização do gado proporcionava carne, leite, couro, força de trabalho, e dinamizava as relações comerciais.

A cozinha de fora

(...) transita com o grupo, limitada nos seus ingredientes e condicionada à natureza, ambulante e com escolhas específicas: o rio, a mata ou o pasto, as idas a Vila ou alguma cidade próxima para comprar mantimentos. Pode ser montada e desmontada quando for conveniente e necessário. Uma cozinha que se movimenta, com o grupo. ${ }^{18}$

Pode-se dizer que a cozinha de fora é predominantemente masculina, tanto em sua manutenção como em seu preparo. Nela é o homem que cozinha, até mesmo devido à ausência de mulheres nos grupos itinerantes. Na cozinha de fora, a forma de cozinhar mais comum é o assado, pelo emprego da fogueira ou do fogareiro. É uma cozinha rústica, na qual se utilizam poucos utensílios, onde se apresenta uma restrita variedade alimentar, em que tem destaque o emprego das raízes, principalmente a mandioca, e também a farinha e a carne-de-sol, ingredientes valorizados por sua facilidade de manuseio, transporte e conservação. No entanto, se é uma cozinha marcada pela escassez, esta reforça a obrigação de estar disposto a dividir um alimento que, frequentemente, está aquém das necessidades dos membros do grupo.

A cozinha de dentro, por outro lado, é doméstica, circunscrita ao espaço da casa. Nela encontram-se presentes as vantagens da vida sedentária, como a maior diversidade de ingredientes e de utensílios, propiciando uma variedade nas técnicas de preparo e receitas, assim como melhores condições para a conservação do alimento por mais tempo. É um

\footnotetext{
${ }^{17}$ Para uma visão histórica do fenômeno da jagunçagem e sua relação com as estruturas de poder, tais como estas se apresentam no romance roseano, cf. VASCONCELOS, Sandra Guardini Teixeira. Homens provisórios. Coronelismo e jagunçagem em Grande sertão: veredas. Scripta, v. 5 n. 10, p. 321-333, 2002.

${ }^{18}$ SANTANA, Ursulina Maria Silva. Ôôôô de Casa... Ôôôô de Fora... As cozinhas em Grande Sertão: veredas e a partilha do alimento como hierofania nos gestos sertanejos. Tese. Doutorado em Ciências da Religião. Pontifícia Universidade Católica de São Paulo, São Paulo. 2014, p. 77.
} 
espaço tipicamente feminino, em que predomina o cozido, o fogo mediado pela água, como técnica de cocção. $\mathrm{O}$ ato de cozinhar se torna mais lento e paciente. Revela-se uma cozinha de acolhimento e conforto, marcada pela hospitalidade.

Nas palavras de Ursulina Santana:

A cozinha de dentro encontra-se no interior de espaço delimitado - a casa. Entra-se nesta cozinha pelo convite, os alimentos oferecidos são produtos recolhidos da natureza e transformados por meio de tecnologias e técnicas de preparo que demandam tempo e elaboração. É fundamental o grupo para saborear a comida preparada. Espaço que se faz necessário à presença do grupo, todos os convidados sob os olhares de quem convidou. A acolhida é fundamental. ${ }^{19}$

A partilha e a dádiva são fundamentais para compreender as relações que se constituem a partir e em torno do alimento e da alimentação. $\mathrm{O}$ doar e o receber a comida não se reduz a uma mera troca comercial, como explicita Ursulina Santana ao comentar a circularidade da dádiva, apoiando-se em Marcel Mauss e Lewis Hyde:

Na circularidade da dádiva percebida pela doação da comida, é possível verificar que não existe barganha. A comida é doada e recebida em sua integridade, de modo que o tecido social permaneça inalterado e sem fissuras. A comida tem um tempo para ser consumida, se não deteriora, de modo que é fundamental que esteja em movimento, circulando nos ambientes onde pode ser encontrada. ${ }^{20}$

Há sempre algo a mais naquilo que é dado/doado ou compartilhado, seja com os outros, seja com Deus. A partilha excede a obrigação de devolver aquilo que foi recebido. Ênio Brito alerta para essa dimensão de acolhimento, que supera a compensação jurídica (o pagar o que se deve) ao colocar em discussão estudos que analisam a relação entre o fiel e o santo:

Hoje, nos estudos das promessas ao santo, tem-se avançado, sem negar a relação contratual (do ut des - perspectiva jurídica) tem-se ido além, explorado o fato do devoto(a) sentir-se acolhido(a), amado(a) pelo(a) santo(a). Tem-se explorado a dimensão de afetividade, tanto que muitas vezes no cumprimento da promessa o devoto(a) vai além daquilo que havia sido prometido. ${ }^{21}$

${ }^{19}$ SANTANA, Ursulina Maria Silva. Ôôôô de Casa... Ô̂ôô de Fora... As cozinhas em Grande Sertão: veredas e a partilha do alimento como hierofania nos gestos sertanejos. Tese. Doutorado em Ciências da Religião. Pontifícia Universidade Católica de São Paulo, São Paulo. 2014, p. 77.

${ }^{20}$ SANTANA, Ursulina Maria Silva. Ôôôô de Casa... Ô̂ôô de Fora... As cozinhas em Grande Sertão: veredas e a partilha do alimento como hierofania nos gestos sertanejos. Tese. Doutorado em Ciências da Religião. Pontifícia Universidade Católica de São Paulo, São Paulo. 2014, p. 99.

${ }^{21}$ BRITO, Ênio José da Costa. O fazer da pesquisa em veredas de religião e história: carpintaria de teses sobre religiosidade popular e afrodiaspórica. São Paulo: Pluralidades, 2021, p. 168. 
Considerando as relações entre alimentação e religião feitas por Ursulina Santana em sua leitura de Grande sertão: veredas, pode-se tecer aproximações entre comensalidade/hospitalidade e religião. Para isso, recorro às funções presentes no conceito de religião discutido por Frank Usarski, apresentado acima.

Pensado enquanto sistema simbólico, o alimento e sua partilha são estruturantes da vida pessoal e social, a partir de dois elementos fundamentais, a escassez e a abundância. Essas duas categorias são referenciadas ao transcendente, sendo o diabo identificado com a escassez, a precariedade, a penúria, enfim, com as dificuldades encontradas na vida, e a abundância, a fartura, relacionados a Deus:

Se a natureza criada por Deus oferece os seus animais e plantas para saciar a fome em momentos de extrema escassez, estabelece uma relação vertical entre a divindade e os homens gerando uma dependência natural. De maneira que essa relação amplia-se quando esses mesmos homens dividem o que caçam, pescam ou colhem compartilhando com seus pares, resultando em laços de solidariedade e compaixão unindo-os novamente a natureza ou Deus, mesmo que se sintam abandonados por Ele. ${ }^{22}$

O alimento, em seu preparo e em sua partilha, é ritualizado, estabelecendo vínculos éticos, de solidariedade e de pertença entre os membros daquela comunidade. Esse pertencimento ou senso de comunidade se torna possível devido ao caráter de dádiva atribuído ao alimento.

O mistério, adjetivo de mística, que segundo Boff e Betto (1994) ${ }^{23}$ "é o vivido cotidianamente na realidade e na experiência de respeito diante da realidade e da vida", proporciona para Riobaldo esse vivido ubicado na realidade sertaneja permitindo o privilégio de estar consigo num nível mais profundo, onde a comida vai permear os encontros, fortalecendo os laços no sertão e consolidar o mistério. $\mathrm{O}$ encontro com o outro, seu igual vai permitir o repartir o alimento e todas as outras funções que permeiam o encontro: hospitalidade, fraternidade, solidariedade, alteridade. A mística onde a natureza é a própria divindade, ofertando o que se precisa para sobreviver, mantendo a vida dada por Deus. ${ }^{24}$

\footnotetext{
${ }^{22}$ SANTANA, Ursulina Maria Silva. Ôôôo de Casa... Ôôôô de Fora... As cozinhas em Grande Sertão: veredas e a partilha do alimento como hierofania nos gestos sertanejos. Tese. Doutorado em Ciências da Religião. Pontifícia Universidade Católica de São Paulo, São Paulo. 2014, p. 98.

${ }^{23}$ A citação interna é de BOFF, Leonardo e BETTO, Frei. Mística e espiritualidade. Rio de Janeiro: Rocco, 1994.

${ }^{24}$ SANTANA, Ursulina Maria Silva. Ôôôô de Casa... Ôôôô de Fora... As cozinhas em Grande Sertão: veredas e a partilha do alimento como hierofania nos gestos sertanejos. Tese. Doutorado em Ciências da Religião. Pontifícia Universidade Católica de São Paulo, São Paulo. 2014, p. 102.
} 
Ursulina Santana compreende que a relação do ser humano com o alimento assumido como dádiva está no fundamento de uma experiência mística. Diferentemente da tradição mística cristã, em que a relação do místico com o divino se realiza por um percurso em que o encontro entre o humano e o transcendente é de natureza volitiva-cognitiva, ${ }^{25}$ a mística sertaneja se manifesta por meio de uma experiência comunitária, para a qual as dimensões de sociabilidade, hospitalidade e comensalidade revelam-se fundantes.

\section{Conclusão}

Religião e literatura são expressões da experiência humana, radicadas na linguagem, e, em particular, em sua dimensão simbólica. A religião, é verdade, transpõe a linguagem simbólica, articulando-se em formas de sociabilidade (rituais) e em práticas éticas. Cada uma a seu modo, religião e literatura são resultado do esforço humano de atribuir sentido à própria existência.

No contexto brasileiro, a literatura por vezes se apropria da linguagem e da simbologia religiosa, interpretando-a ou mesmo interpelando-a. Em um país construído sobre relações fortemente violentas e assimétricas, é como se a literatura buscasse na religião categorias que pudessem atribuir sentido a uma realidade onde predominam o não-sentido da morte, do sofrimento, da injustiça e da fome.

O romance Grande sertão: veredas, de Guimarães Rosa, propicia múltiplas interpretações no que toca a presença da linguagem e da simbologia religiosa. Ursulina Santana, ao pesquisar as cozinhas de dentro e de fora, explorou uma perspectiva até então pouco considerada, embora presente no centro da tradição cristã, no mistério pascal: a partilha do alimento como via de acesso ao transcendente. A obtenção, o preparo e a partilha do alimento estabelecem e reforçam vínculos de sociabilidade, comensalidade e hospitalidade, humanizam e sacralizam as relações entre as pessoas, o que se mostra ainda mais significativo em contextos de escassez e precariedade.

Retomar a dimensão sacramental, mística, do alimento, parece ainda mais relevante em um momento em que milhões de brasileiras e brasileiros se encontram em situação de insegurança alimentar. Situação que resulta da infeliz opção político-econômica pelo neoliberalismo, em que o Estado se converte em instrumento do capital financeiro internacional, renunciando a sua função de proteção da cidadania e de promotor do

\footnotetext{
${ }^{25}$ Cf. VAZ, Henrique C. de Lima. Experiência mítica e filosofia na tradição ocidental. São Paulo: Loyola,
} 2000 . 
investimento produtivo, gerador de riqueza e renda, e que foi agravada nos últimos dois anos devido à pandemia da Covid-19. ${ }^{26}$

Ficam abertas diversas possibilidades de abordagem das relações entre religião e literatura brasileira, das quais menciono somente algumas trabalhadas em pesquisas recentes: as representações literárias do mal, centradas ou não na figura do demônio; ${ }^{27} \mathrm{o}$ diálogo da literatura com as tradições africanas e afro-brasileiras; ${ }^{28}$ a presença da religiosidade popular na literatura de folhetos, também chamada literatura de cordel. ${ }^{29}$

\section{Referências}

BOFF, Leonardo e BETTO, Frei. Mística e espiritualidade. Rio de Janeiro: Rocco, 1994.

BOFF, Leonardo. Os sacramentos da vida e a vida dos sacramentos: minima sacramentalia. 26. ed. Petrópolis: Vozes, 2004.

BRITO, Ênio José da Costa. O fazer da pesquisa em veredas de religião e história: carpintaria de teses sobre religiosidade popular e afrodiaspórica. São Paulo: Pluralidades, 2021.

CÂNDIDO, Antonio. de. Vários escritos. 5. ed. Rio de Janeiro: Ouro sobre azul, 2011.

COSTA, Neffertite Marques da. Nossa Senhora dos Cordéis: a figura de Maria nos folhetos de Minelvino Francisco Silva e Rodrigo Coelho Cavalcante. Salvador: Sagga, 2020 .

FRUTUOSO, Maria Fernanda Petroli e VIANA, Cássio Vinícius Afonso. "Quem inventou a fome são os que comem": da invisibilidade à enunciação-uma discussão necessária em tempos de pandemia. Interface-Comunicação, Saúde, Educação, v. 25, $2021 . \quad$ Disponível em: https://www.scielo.br/j/icse/a/LPHP93S94TgNtKbGtRZtDcs/?lang=pt\&format=html. Acesso em: 24/11/2021.

MAGALHÃES, Antonio Carlos de Mello et al. (Orgs.). O demoníaco na literatura. Campina Grande: EDUEPB, 2012.

\footnotetext{
${ }^{26}$ Sobre o agravamento da insegurança alimentar no Brasil no contexto pandêmico, cf. FRUTUOSO, Maria Fernanda Petroli e VIANA, Cássio Vinícius Afonso. "Quem inventou a fome são os que comem": da invisibilidade à enunciação-uma discussão necessária em tempos de pandemia." Interface-Comunicação, Saúde, Educação, v. 25, 2021. NEVES, José Anael et al. Desemprego, pobreza e fome no Brasil em tempos de pandemia por Covid-19. Revista de Nutrição, v. 34, 2021.

${ }^{27}$ Cf. MAGALHÃES, Antonio Carlos de Mello et al. (Orgs.). O demoníaco na literatura. Campina Grande: EDUEPB, 2012.

${ }^{28}$ Cf. PIMENTEL, C. S. Memória brasileira em Áfricas: da convivência à narrativa ficcional. Jundiaí: Paco, 2016.

${ }^{29}$ Cf. COSTA, Neffertite Marques da. Nossa Senhora dos Cordéis: a figura de Maria nos folhetos de Minelvino Francisco Silva e Rodrigo Coelho Cavalcante. Salvador: Sagga, 2020.
} 
MANZATTO, Antonio. Pequeno panorama de teologia e literatura. In: MARIANI, Ceci Baptista e VILHENA, Maria Angela. (Orgs.). Teologia e arte: expressões de transcendência, caminhos de renovação. São Paulo: Paulinas, 2011.

MARIANI, Ceci Baptista. e OTTEN, Heinrich Alexander. A arte como expressão da experiência espiritual: experiência de revelação e caminho de transformação. In: MARIANI, Ceci Baptista e VILHENA, Maria Angela. (Orgs.). Teologia e arte: expressões de transcendência, caminhos de renovação. São Paulo: Paulinas, 2011.

MENESES, Adélia Bezerra de. O 'Quem' dos lugares. A passionalização da natureza em Grande sertão: veredas. Scripta, v. 9, n. 17, p. 29-39, 2005. Disponível em: http://seer.pucminas.br/index.php/scripta/article/view/14076. Acesso em: 30/09/2021.

NEVES, José Anael et al. Desemprego, pobreza e fome no Brasil em tempos de pandemia por Covid-19. Revista de Nutrição, v. 34, 2021. Disponível em: https://www.researchgate.net/profile/Jose-Neves-

30/publication/352065007_Unemployment_poverty_and_hunger_in_Brazil_in_Covid19_pandemic_times/links/60b80b56a6fdccb96f4d857a/Unemployment-poverty-andhunger-in-Brazil-in-Covid-19-pandemic-times.pdf. Acesso em: 24/11/2021.

PIMENTEL, Claudio Santana. Humanização do divino, divinização do humano: representações do imaginário religioso no teatro de Ariano Suassuna. Dissertação. Mestrado em Ciências da Religião. Pontifícia Universidade Católica de São Paulo. São Paulo, 2010.

PIMENTEL, Claudio Santana. Memória brasileira em Áfricas: da convivência à narrativa ficcional. Jundiaí: Paco, 2016.

ROSA, João Guimarães. Grande sertão: veredas. 19. ed. Rio de Janeiro: Nova Fronteira, 2001.

SANTANA, Ursulina Maria Silva. Ôôôo de Casa... Ôôôo de Fora... As cozinhas em Grande Sertão: veredas e a partilha do alimento como hierofania nos gestos sertanejos. Tese. Doutorado em Ciências da Religião. Pontifícia Universidade Católica de São Paulo, São Paulo. 2014.

SILVA, Antonio Ozaí da. Preconceito e intolerância religiosa em "O pagador de promessas". Revista Espaço Acadêmico, v. 7, n. 73, 2007. Disponível em: https://periodicos.uem.br/ojs/index.php/EspacoAcademico/article/download/59102/751 375152167/. Acesso em 24/11/2021.

TENÓRIO, Waldecy. A bailadora andaluza: a explosão do sagrado na poesia de João Cabral. Cotia: Ateliê Editorial, 1996.

TENÓRIO, Waldecy. Outras verdades, muito extraordinárias. Estudos avançados, v. 20, 89-96, 2006.2 Disponível em: https://www.scielo.br/j/ea/a/XBFGrVvnXWQwVyjgbSkZnmB/?lang=pt\&format=pdf Acesso em: 30/09/2021. 
USARSKI, Frank. Constituintes da ciência da religião: cinco ensaios em prol de uma disciplina acadêmica. São Paulo: Paulinas, 2006.

VASCONCELOS, Sandra Guardini Teixeira. Homens provisórios. Coronelismo e jagunçagem em Grande sertão: veredas. Scripta, v. 5 n.10, p. 321-333, 2002. Disponível em: http://periodicos.pucminas.br/index.php/scripta/article/view/12410. Acesso em: 30/09/2021.

VAZ, Henrique C. de Lima. Experiência mítica e filosofia na tradição ocidental. São Paulo: Loyola, 2000. 